\title{
Synthesis and enzymatic degradation of randomly substituted 2,3,6-O-cellulose acetate and regioselectively substituted $2,3-O$-cellulose acetate
}

Nobuko Takeda, Yukiko Enomoto-Rogers, Akio Takemura, and Tadahisa Iwata*

Science of Polymeric Materials, Department of Biomaterial Sciences, Graduate School of Agricultural and Life Sciences, The University of Tokyo, 1-1-1 Yayoi, Bunkyo-ku, Tokyo 113-8657, Japan

*Corresponding author. Tel: +81-3-5841-5266; Fax: +81-3-5841-1304.

E-mail: atiwata@mail.ecc.u-tokyo.ac.jp

\begin{abstract}
To investigate the effect of substitution site on enzymatic degradation property of cellulose acetate (CA), randomly substituted 2,3,6-O-CA (DS $=0.4,1.2$, and 2.1) and regioselectively substituted 2,3-O-CA (DS $=0.4,1.3$, and 2.0) were synthesized without or with using trytyl group for C6 protection process. Both 2,3,6-O-CA and 2,3-O-CA were submitted to enzymatic degradation test using cellulase from Toricoderma reesei. The concentration of hydrolytic products was analyzed by the reducing sugar analyses using glucose standards. CAs with lower DS (0.4) were more hydrolyzed compared to CAs with higher DS (1.2 or 1.3) and CAs with DS over 2 were not hydrolyzed regardless of substitution site. The degradability of 2,3-O-CAs (DS $=0.4$ and 1.3) turned out to be higher than that of 2,3,6-O-CAs (DS $=0.4$ and 1.2). The hydrolytic products of 2,3,6-O-CA and 2,3-O-CA were analyzed by HPLC and the relationship between their substitution site and the enzymatic degradation behavior was discussed in detail.
\end{abstract}

Keywords: Cellulose acetate, regioselective substitution, enzymatic degradation, cellulase

\section{Introduction}

Cellulose is one of the most abundant polysaccharides produced by nature, such as plants or microorganisms. It has been recognized as renewable resource and expected to be important bio-based material as alternative of petroleum-based plastics. Cellulose is also considered as environmentely friendly material because it is biodegradable and kown to be degraded by cellulase enzymes, which cleave glycosyl bonds via hydrolysis. From the point of view of application, cellulose is consisting of $\beta(1 \rightarrow 4)$ anhydro glucose units, and has no plasticity itself due to inter- and intra- molecular hydrogen bondings and esterification of hydroxyl groups of cellulose chains are effective way to alter its property to thermoplastic.

Cellulose acetate (CA) is well known as the most important cellulose ester, which is 
widely used as plastic materials, such as filters or fibers $[1,2]$. CAs have also been widely recognized as biodegradable under both aerobic and anaerobic conditions when its degree of substitution (DS) is less than 2.5 [3-5]. There have also been some reports on biodegradablity of CA in composite [6-9]or on its enzymatic hydrolysis [10-13]. In these previous stusies, acetyl groups were randomly introduced into all $\mathrm{C} 2, \mathrm{C} 3$, and $\mathrm{C} 6$ positions, and their degradability have been investigated in association with the effect of degree of substitution (DS) [14, 15].

Regarding the relationship between chemical structure and biodegradability of CA, the substitution site of acetyl groups is quite important factor. Rosser et.al investigated the effect of substitution site on enzymatic degradability of acetyl amylose and reported that susceptibility to enzymatic degradation by amylase was in the order of 2,3-O-, 2,3,6-O-, 6-O-acetyl amylose [16]. In the case of $\mathrm{CA}$, substitution site would also be important factor to control its biodegradability for its wide range of application. However, to our knowledge, there is no report on the detailed relationship between substitution site and degradability of CA.

In the present study, we have preapred regioselectively substituted cellulose acetate (CA), namely, 2,3-O-CA with different degree of substitution (DS). We have also investigated the effect of substitution site on their degradability by cellulase and compared its degradability with that of randomly substituted 2,3,6-O-CA. 


\section{Experimental}

\section{Materials}

Cellulose (Whatman CF1) was purchased from Funakoshi Co., Ltd (Tokyo, Japan). All other reagents were commercially obtained and used without further purification. Dialysis membrane 36-32-100 (MWCO 14000) was purchased from Viskase Companies, Inc. (Darien, IL, USA).

\section{2,3,6-O-cellulose acetate $(2,3,6-O-C A)$}

Representative 2,3,6-O-CA with degree of substitution (DS) of 1.2 is as follows; Dried cellulose $(1.0 \mathrm{~g})$ was suspended in DMAc $(20 \mathrm{~mL})$ and stirred at $120^{\circ} \mathrm{C}$ for $2 \mathrm{~h}$. After the slurry was allowed to cool to $100^{\circ} \mathrm{C}$, anhydrous $\mathrm{LiCl}(1.8 \mathrm{~g})$ was added and stirred at room temperature for 3 days. To this homogeneous solution, pyridine $(5 \mathrm{~mL})$ and acetic anhydride $(5 \mathrm{~mL})$ were added. The mixture was stirred at $40{ }^{\circ} \mathrm{C}$ for $2.0 \mathrm{~h}$ to allow acetylation. After the reaction, the mixture was poured into ethanol $(2.0 \mathrm{~L})$. The precipitate was filtered, washed with ethanol, and dried in vacuo to give 2,3,6-O-CA (DS=1.2) (1.1 g, $82.3 \%$ yield). 2,3,6-O-CA with DS of $0.4,1.2$ were prepared by acetylation for $0.5 \mathrm{~h}$ and $3.0 \mathrm{~h}$, respectively.

\section{Perpropionylation of 2,3,6-O-CA for DS determination}

2,3,6-O-CAs were propionylated to determine DS of acetyl groups. 2,3,6-O-CAs (50 $\mathrm{mg}$ ) were stirred in a solution of pyridine $(3 \mathrm{~mL})$ and propionic anhydride $(3 \mathrm{~mL})$ for 1 day at $60{ }^{\circ} \mathrm{C}$. The mixture was poured in excess amount of ethanol with stirring followed by filtration, and dried in vacuo to give perpropionylated 2,3,6-O-CA (total DS of 3.0) (78.5 mg, quantitative). The DS of the acetyl groups was calculated by subtracting the DS of propyonyl group from total DS of 3.0, as follows, acetyl DS $=3.0$ - propyonyl DS. The DS of propyonyl group was calculated from the ratio of the integrated areas of the methyl protons of the propyonyl group to the ring protons of glucose unite based on ${ }^{1} \mathrm{H}-\mathrm{NMR}$ spectrum, as follows: propyonyl DS $=\left(\left[\mathrm{CH}_{3}(\mathrm{Pr})\right] / 3\right) /\left([\right.$ ring-H]/7)$) .{ }^{1} \mathrm{H}-\mathrm{NMR}\left(\mathrm{CDCl}_{3}\right): \delta 1.1\left(\mathrm{CH}_{3}(\mathrm{Pr})\right)$, 1.9-2.2 ( $\left.\mathrm{CH}_{3}(\mathrm{Ac}), \mathrm{CH}_{2}(\mathrm{Pr})\right)$, 3.5- 5.1 (ring-H).

\section{6-O-trityl cellulose}

Dried cellulose $(5.0 \mathrm{~g})$ was suspended in DMAc $(100 \mathrm{~mL})$ and stirred at $120^{\circ} \mathrm{C}$ for $2 \mathrm{~h}$. After the slurry was allowed to cool to $100^{\circ} \mathrm{C}$, anhydrous $\mathrm{LiCl}(8.6 \mathrm{~g})$ was added and stirred at room temperature for 3 days. To this homogeneous solution, pyridine $(11.2 \mathrm{~mL})$ and trityl chloride $(19.3 \mathrm{~g})$ were added and stirred at $70{ }^{\circ} \mathrm{C}$ for 2 days. After the reaction, the mixture was poured into ethanol $(2.0 \mathrm{~L})$. The precipitate was filtered, washed with ethanol, and dried in vacuo to give 6-O-trytyl cellulose ( $8.0 \mathrm{~g}, 64.1 \%$ yield $)$.

\section{2,3-O-acetyl-6-O-trityl cellulose}


Representative 2,3-O-acetyl-6-O-trityl cellulose with degree of acetyl substitution (DS) of 1.3 is as follows; To a solution of 6-O-trityl cellulose $(2.0 \mathrm{~g})$ in pyridine $(15 \mathrm{~mL})$, acetic anhydride $(15 \mathrm{~mL})$ was added and stirred at $60{ }^{\circ} \mathrm{C}$ for 10 minutes to allow acetylation. After the reaction, the mixture was poured into ethanol $(2.0 \mathrm{~L})$. The precipitate was filtered, washed with ethanol, and dried in vacuo to give 2,3-O-acetyl-6-O-trityl cellulose (acetyl DS = 1.3) (2.2 g, $96.9 \%$ yield). 2,3-O-acetyl-6-O-trityl cellulose with acetyl DS of 0.4 and 2.0 were prepared by acetylation at $40^{\circ} \mathrm{C}$ for 10 minutes and at $60{ }^{\circ} \mathrm{C}$ for $18 \mathrm{~h}$, respectively.

\section{Perpropionylation of 2,3-O-acetyl-6-O-trityl cellulose for DS determination}

2,3-O-acetyl-6-O-trityl celluloses were propionylated to determine DS of acetyl groups. 2,3-O-acetyl-6-O-trityl celluloses $(50 \mathrm{mg})$ were stirred in a solution of pyridine $(3 \mathrm{~mL})$ and propionic anhydride $(3 \mathrm{~mL})$ for 1 day at $60{ }^{\circ} \mathrm{C}$. The mixture was poured in excess amount of ethanol with stirring followed by filtration, and dried in vacuo to give perpropionylated 2,3-O-acetyl-6-O-trityl cellulose (total DS of 3.0) (34.3 mg, quantitative). The DS of the acetyl groups was calculated by subtracting the DS of propyonyl group from total DS of 2.0, as follows, acetyl DS $=2.0$ - propyonyl DS. The DS of propyonyl group was calculated from the ratio of the integrated areas of the methyl protons of the propyonyl group to the ring protons of glucose unite based on ${ }^{1} \mathrm{H}-\mathrm{NMR}$ spectrum, as follows: propyonyl $\mathrm{DS}=$ $\left(\left[\mathrm{CH}_{3}\right] / 3\right) /([\mathrm{ring}-\mathrm{H}] / 7) .{ }^{1} \mathrm{H}-\mathrm{NMR}\left(\mathrm{CDCl}_{3}\right): \delta 1.1\left(\mathrm{CH}_{3}(\mathrm{Pr})\right), 1.9-2.2\left(\mathrm{CH}_{3}(\mathrm{Ac}), \mathrm{CH}_{2}(\mathrm{Pr})\right)$, 3.4- 5.2 (ring-H), 7.3 (trytyl).

\section{2,3-O-cellulose acetate (2,3-O-CA)}

Representative procedure is as follows; To a solution of 2,3-O-acetyl-6-O-trityl cellulose $(\mathrm{DS}=1.3)(2.2 \mathrm{~g})$ in chloroform $(60 \mathrm{~mL})$ in acetic acid $(8.0 \mathrm{~mL}), 30 \% \mathrm{HBr}$ in acetic acid $(4.0 \mathrm{ml})$ was added under vigorous stirring at room temperature. The mixture was stirred for 5 minutes. After the reaction, the precipitate was filtered, immediately washed by $\mathrm{NaHCO}_{3}$ aqueous solution, water, ethanol, and dried in vacuo to give 2,3-O-CA $(\mathrm{DS}=1.3)(0.1 \mathrm{~g}, 10.6 \%$ yield $)$. 2,3-O-CA ( $\mathrm{DS}=0.4)$ was purified and collected by dialysis against water after precipitation.

\section{Preparation of cellulose by deacetylation of CAs}

To a solution of 2,3,6-O-CA $\left(\mathrm{DP}_{\mathrm{n}}=248\right)(300 \mathrm{mg})$ in methanol $(1 \mathrm{~mL})$ and chloroform $(30 \mathrm{~mL}), 28 \%$ sodium methoxide/methanol $(1.8 \mathrm{~mL})$ was added and stirred at room temperature for 1 day. After the reaction, methanol $(8.0 \mathrm{~mL})$ was added to the reaction

mixture, and the precipitate was filtered, washed by methanol, dried to give cellulose $\left(\mathrm{DP}_{\mathrm{n}}=\right.$ 248). Cellulose $\left(\mathrm{DP}_{\mathrm{n}}=54\right)$ was prepared by deacetylation of 2,3-O-CA $(\mathrm{DS}=2)\left(\mathrm{DP}_{\mathrm{n}}=54\right)$ in $8.7 \% \mathrm{LiCl} / \mathrm{DMAc}$ solution in the same manner. 


\section{Nuclear magnetic resonance (NMR) measurements}

NMR spectrum was recorded with JEOL JNM-A500 FT-NMR (500MHz) spectrometer, using tetramethylsilane (TMS) as an internal standard. Samples for NMR analyses were prepared by dissolving $10 \mathrm{mg}$ of the prepared compounds in $0.5 \mathrm{~mL}$ of chloroform- $d$ or DMSO-d6.

\section{Gel permeation chromatography (GPC) measurements}

Number - and weight - average molecular weights $\left(M_{\mathrm{n}}\right.$ and $\left.M_{\mathrm{w}}\right)$ and polydispersity index values $\left(M_{\mathrm{n}} / M_{\mathrm{w}}\right)$ of CAs were estimated by GPC (CBM-20A, DGU-20A3, LC-6AD, SIL-20ACHT, CTO-20A, RID-10A, Shimazu) in chloroform at $40{ }^{\circ} \mathrm{C}$. Shodex columns (K-806M, K-802) were used, and the flow rate was $0.6 \mathrm{~mL} / \mathrm{min}$. A calibration curve was obtained using polystyrene standards (Shodex). Degree of polymerization (DPn) of 2,3,6-O-CA was calculated from the molecular weight of cellulose triacetate prepared by complete acetylation of original cellulose. The $M_{\mathrm{w}}$ and $M_{\mathrm{n}}$ and $M_{\mathrm{w}} / M_{\mathrm{n}}$ of 2,3,6-O-CA (DS = 3.0) were $M_{\mathrm{w}}=1.1 \times 10^{5}, M_{\mathrm{n}}=7.2 \times 10^{4}, M_{\mathrm{w}} / M_{\mathrm{n}}=1.6$, respectively, and $\mathrm{DP}_{\mathrm{n}}$ of 2,3,6-O-CA was calculated to be $\mathrm{DP}_{\mathrm{n}}=248$. $\mathrm{DP}_{\mathrm{n}}$ of 2,3-O-CA was calculated from the molecular weight of cellulose triacetate prepared by complete acetylation of 2,3-O-CA after removal of trityl group by $\mathrm{HBr}$. The $M_{\mathrm{w}}, M_{\mathrm{n}}$, and $M_{\mathrm{w}} / M_{\mathrm{n}}$ of peracetylated 2,3-O-CA were $M_{\mathrm{w}}=3.2 \times 10^{4}, M_{\mathrm{n}}=$ $1.6 \times 10^{4}, M_{\mathrm{w}} / M_{\mathrm{n}}=2.0$, respectively, and $\mathrm{DP}_{\mathrm{n}}$ of 2,3-O-CA was calculated to be $\mathrm{DP}_{\mathrm{n}}=54$.

\section{HPLC measurements}

The hydrolytic products of CA were analyzed by HPLC (CBM-20A, DGU-20A3R, LC-20AD, SIL-20AC, CTO-20A, RID-10A, Shimazu) in distilled water at $80{ }^{\circ} \mathrm{C}$. Shodex columns (KS-802) was used, and the flow rate was $0.6 \mathrm{~mL} / \mathrm{min}$. Glucose $(\mathrm{G})$ (Wako Pure Chemical Industries, Ltd.), maltose (G2), maltotriose (G3), maltotetraose (G4), maltopentaose (G5), maltoheptaose (G6) (Hayashibara), maltohexaose (G7), (Tronto research chemicals Inc.) and pullulan (MW $=6100$ and 9100) (Shodex) were used as standards.

\section{Enzymatic degradation test}

Cellulase from Trichoderma reesei ATCC26921, 700u/g aq (Celluclast ${ }^{\circledR}$, Novozyme) was used to study the enzymatic degradation of the prepared CAs as substrate. Enzyme concentration was set to 0.7 or $7 \mathrm{u} / \mathrm{mL}$. Each substrate $(10 \mathrm{mg})$ was suspended in $\mathrm{pH} 5$ acetate buffer $(1.0 \mathrm{~mL})$ and was incubated at $40^{\circ} \mathrm{C}, 130 \mathrm{rpm}$ for fixed period of time after enzyme solution was added. Each sample was then centrifuged at $5000 \mathrm{rpm}$ for $5 \mathrm{~min}$. To an one portion of the supernatant solution $(250 \mu \mathrm{L}), 1 \mathrm{M}$ sodium hydroxide aqueous solution $(250 \mu \mathrm{L})$ was added to deactivate cellulase enzyme, and the obtained solution $(500 \mu \mathrm{L})$ was submitted to reducing sugars analyses. The reaction mixture left was boiled to deactivate cellulase enzyme and centrifuged. The supernatant solution $(100 \mu \mathrm{L})$ was then diluted with 
water $(1.0 \mathrm{~mL})$ and submitted to HPLC analyses. Substrate concentration $(10 \mathrm{mg} / \mathrm{mL})$ was high enough to ignore the effect of molar concentration on enzyme activity, so the difference in molecular weight was not considered. The concentrations of hydrolytic products of CAs were analyzed by measurement of reducing sugar concentration using $p$-hydroxybenzoic acid hydrazide (PHBAH) as color regent. $1.5 \%$ PHBAH solution was prepared by dissolving PHBAH (7.6 g), potassium sodium tartrate (28.2 g), and sodium hydroxide (10.2 g) in distilled water $(500 \mathrm{~mL}) . \quad 1.5 \%$ PHBAH solution $(500 \mu \mathrm{L})$ was added to the deactivated enzyme - substrate solution $(500 \mu \mathrm{L})$ (see above) and heated in boiling water for $10 \mathrm{~min}$. After cooling for $10 \mathrm{~min}$, the absorbance at $405 \mathrm{~nm}$ was measured to determine amount of reducing sugars using the spectrophotometers U-2910 (Hitachi). Absorbance was converted into the quantity of reducing sugar concentration by using a calibration curve generated by glucose standards.

\section{Results and Discussion}

\section{Preparation of 2,3,6-O-CA and 2,3-O-CA}

Randomly substituted 2,3,6-O-CAs (DS $=0.4,1.2,2.1$ ) were prepared by homogeneous acetylation of cellulose in acetic anhydride and pyridine according to the previously reported method [17]. Regioselectively substituted 2,3-O-CA (DS = 0.4, 1.3, 2.0) were prepared via 3 steps including 6-O-tritylation, 2,3-O-acetylation, and subsequent de-tritylation based on the previous studies $[18,19]$. DS values were controlled by varying temperature and reaction time. To improve the solubility of CAs in the solvent for NMR analyses, residual free hydroxyl groups were perpropionylated and chemical structures were identified by NMR measurements. The representative ${ }^{1} \mathrm{H}-\mathrm{NMR}$ spectra of perpropionylated 2,3,6-O-CA (DS = 1.2) and perpropionylated 2,3-O-acetyl-6-O-trytyl cellulose (DS = 1.3) are shown in Figures $2 \mathrm{a}$ and $2 \mathrm{~b}$, respectively. The DS values of acetyl groups were calculated from the integral peak area of acetyl or propionyl groups and ring protons based on ${ }^{1} \mathrm{H}-\mathrm{NMR}$ analyses, as described in experimental section and listed in Table1. The ${ }^{13} \mathrm{C}-\mathrm{NMR}$ analyses of 2,3,6-O-CA ( $\mathrm{DS}=1.2$ ) revealed that the three peaks attributed to acetyl carbonyl carbons were observed, indicating that acetyl groups were randomly introduced into all $\mathrm{C} 2, \mathrm{C} 3$, and C6 positions (Figure 2c). It is noted that the preference of substitution in the order of $\mathrm{C} 6, \mathrm{C} 2$, and $\mathrm{C} 3$ were indicated by the peak intensity of carbonyl groups at each positions. In the case of 2,3-O-CA, the two carbonyl carbon peaks due to acetyl groups at $\mathrm{C} 2$ and $\mathrm{C} 3$ were observed (Figure 2d), indicating that hydroxyl groups at $\mathrm{C} 6$ is remaining without acetylation. Based on the previously reported study [20], their individual DS at the C2, C3, and C6 positions were calculated from peak area ratio of acetyl carbonyl carbons and summarized in Table1. Regarding the distribution of acetyl groups, NMR analyses can give only "average" molar value of acetyl groups to anhydroglucose unit (AGU). Therefore, it should be noted that acetyl groups might be localized in inter- and intra-molecular level as well as distributed 
evenly in all AGU along all molecular chains. The obtained CA samples were insoluble in chloroform and their molecular weight could not be measured by GPC. Therefore, molecular weights of peracetylated 2,3,6-O-CA and 2,3-O-CA were measured as representatives by GPC and degrees of polymerization $\left(\mathrm{DP}_{\mathrm{n}}\right)$ of the peracetylated samples were used as the representative $\mathrm{DP}_{\mathrm{n}}$ values of 2,3,6-O-CA and 2,3-O-CA used in this study. $\mathrm{DP}_{\mathrm{nS}}$ of 2,3,6-O-CA and 2,3-O-CA were calculated as 248 and 54, respectively, as shown in Table 1. The decrease in $\mathrm{DP}_{\mathrm{n}}$ of 2,3-O-CA was due to hydrolysis by $\mathrm{HBr}$ in acidic condition.

\section{Initial degradation rate of CAs}

2,3,6-O-CA (DS $=0.4,1,3,2.1)$ and 2,3-O-CA (DS $=0.4,1,2,2.0)$ were incubated with cellulase as degradation enzyme. In order to evaluate and compare the degradability of CAs, we initially tried to determine initial degradation rate $(v)$ by taking a slope value over the range of short incubation time in the plots which exhibit a linear line under low enzyme concentration $(0.7 \mathrm{u} / \mathrm{mL})$. The CA samples were insoluble in buffer solution, accordingly incubated in heterogeneous system. Figure $3 \mathrm{a}$ and $3 \mathrm{~b}$ show the plots of the reducing sugar concentration of degraded products of 2,3,6-O-CA and 2,3-O-CA in buffer solution as function of incubation time, respectively. The reducing sugar concentration indicates the concentration of low molecular weight sugar components generated by enzymatic degradation. With regard to 2,3,6-O-CA, the reducing sugar concentration remained $0.0 \mathrm{mM} / \mathrm{h}$ and there was no increase in its value for $3 \mathrm{~h}$ observation time with regardless of DS values, indicating that 2,3,6-O-CAs were not degraded at this enzyme concentration. In the case of 2,3-O-CAs, the reducing sugar concentration showed rapid increase after the 30 minute incubation for 2,3-O-CAs with DS of 0.4 and 1.3, indicating the degradability of these 2,3-O-CAs at this enzyme concentration. The $v$ of 2,3-O-CA with DS of 0.4 and 1.3 were calculated to be 11.4 and $10.2 \mathrm{mM} / \mathrm{h}$, respectively, by the slope of the initial liner region. The reducing sugar concentration of 2,3-O-CA (DS $=2.0$ ) showed no increase, which is indicative to no degradability of 2,3-O-CA (DS $=2.0$ ). The $v$ values were calculated to be $0.0 \mathrm{mM} / \mathrm{h}$ for $2,3,6-O-\mathrm{CA}(\mathrm{DS}=0.4,1,2,2.1)$ and $2,3-O-\mathrm{CA}(\mathrm{DS}=2.0)$. We could not find the common enzyme concentration that can compare the $v$ values of all CA samples in the same condition because the degradation of 2,3,6-O-CAs was too low compared to 2,3-O-CAs. Above this enzyme concentration of $0.7 \mathrm{u} / \mathrm{mL}$, the reducing sugar concentration of hydrolytic products from 2,3-O-CAs no longer increased in linear form and increased rapidly in short time. Taken together with these results, it was suggested that 2,3-O-CA had higher degradability than 2,3,6-O-CA.

\section{Long term degradation of CAs}

We then proceeded to investigate the degradation of CAs at higher enzyme concentration $(7.0 \mathrm{u} / \mathrm{mL}) . \quad 2,3,6-O-\mathrm{CA}(\mathrm{DS}=0.4,1,3,2.1)$ and 2,3-O-CA $(\mathrm{DS}=0.4,1,2,2.0)$ were 
incubated in longer term up to 12 hours. Cellulose samples with DP of 248 and 54 were prepared by deacetylation of 2,3,6-O-CA $\left(\mathrm{DS}=3, \mathrm{DP}_{\mathrm{n}}=248\right)$ and 2,3-O-CA $\left(\mathrm{DS}=2, \mathrm{DP}_{\mathrm{n}}=\right.$ 54 ), respectively, to examine the effect of molecular weight on the measured values of the reducing sugar concentration.

The plots of the reducing sugar concentration for 2,3,6-O-CA (DS $=0.4,1,3,2.1$ ) are shown in Figure 4a. 2,3,6-O-CA (DS = 0.4) showed slight increase to 12 hours. 2,3,6-O-CA (DS $=1.3,2.0$ ) showed no increase, indicating that these CAs had quite low degradability at this condition. As shown in Figure 4b, 2,3-O-CA (DS $=0.4,1.3)$ produced hydrolytic products after 30 minutes incubation and their reducing sugar concentration were $6.8 \mathrm{mM}$ and $3.0 \mathrm{mM}$ at, respectively. The reducing sugar concentration increased until 6 hour incubation and showed no increase after. 2,3-O-CA (DS = 2.0) showed no increase in reducing sugar concentration during 12 hour incubation, suggesting its low degradability. When DS was above 2.0 both 2,3,6-O-CA and 2,3-O-CA showed no degradability, which was independent on substitution site. From the point of view of DS, in the case of both 2,3,6-O-CA and 2,3-O-CA, the compounds with lower DS showed higher degradability compared to those with higher DS.

\section{Effect of substitution site on degradation}

In order to investigate the effect of substitution site on degradability, 2,3,6-O-CA and 2,3-O-CA with the same DS values need to be compared. In the previous study on amylose acetate with the molecular weight of 5000 and 20000, there was no effect of molecular weight on the reducing sugar concentration of the hydrolytic products. However, in the present study, the absolute values of the reducing sugar concentration for low DP cellulose $\left(\mathrm{DP}_{\mathrm{n}}=54\right)$ was higher than that of high DP cellulose $\left(\mathrm{DP}_{\mathrm{n}}=248\right)$ as shown in Figure $4 \mathrm{a}$ and $4 \mathrm{~b}$. It was likely because low DP cellulose $\left(\mathrm{DP}_{\mathrm{n}}=54\right)$ produced more amount of water soluble hydrolytic products with low molecular weight than high DP cellulose $\left(\mathrm{DP}_{\mathrm{n}}=248\right)$ at the same enzymatic activity. This means that low DP cellulose gives higher reducing sugar concentration compared to high DP cellulose and that degradability for low DP cellulose might be overestimated compared to high DP cellulose. Therefore, the degradability of 2,3,6-O-CA and 2,3-O-CA was evaluated by taking its reducing sugar concentration relative to that of cellulose with the corresponding DP to exclude the effects of DP on the reducing sugar concentration value of hydrolytic products.

The relative reducing sugar concentration for CAs to cellulose with same DP was plotted as function of incubation time (Figure 5). The reducing sugar concentration of 2,3,6-O-CA (DS $=0.4$ and 1.3 ) decreased to about $50 \%$ and $30 \%$ of that of high DP cellulose at $12 \mathrm{~h}$ incubation as shown in Figure 5a. With respect to 2,3-O-CAs, it is noteworthy that 2,3-O-CA (DS = 0.4) showed higher degradability (ca. $146 \%$ ) compared to low DP cellulose at 1 hour incubation as shown in Figure 5b. We attributed this result to the difference in 
hydrogen bonding formation. Cellulose is highly crystalline due to strong inter- and intra-molecular hydrogen bonding and amorphous cellulose is known to be degraded easily than crystalline cellulose [21]. In fact, 2,3-O-CA (DS=0.4) showed better affinity for water and we suggest that it allowed efficient enzyme binding on cellulose chain and resulting higher degradability of CA. The relative reducing sugar concentration of 2,3-O-CA (DS = 0.4 and 1.3) to low DP cellulose was more than $80 \%$ and $70 \%$ (Figure 5b), respectively, suggesting that 2,3-O-CA retained 80 and $70 \%$ degradability relative to cellulose. These results revealed that regioselectively substituted 2,3-O-CA (DS $=0.4$ and 1.3) had higher degradability compared to 2,3,6-O-CA at the same DS. It has also been reported that susceptibility to enzymatic degradation was in the order of 2,3-O-, 2,3,6-O-, 6-O-acetyl amylose [16]. It was strongly suggested that degradability of CA is significantly inhibited by $\mathrm{C} 6$ substitution and resulting prevention of hydrogen bond formation.

\section{HPLC analyses}

The HPLC profiles of the hydrolytic products of $2,3,6-O-\mathrm{CA}$ (DS $=0.4,1.2,2.1$ ) and 2,3-O-CA (DS $=0.4,1.3,2.0$ ) after $12 \mathrm{~h}$ incubation were shown in Figure $6 \mathrm{a}$ and $6 \mathrm{~b}$, respectively, with a comparison with the cellulose samples with corresponding $\mathrm{DP}_{\mathrm{n}}$. The hydrolytic products were consisting of only water-soluble oligomers and the un-hydrolyzed water-insoluble residues were not included. HPLC profiles of malto-oligomers were used as standards for comparison with the degree of polymerization of hydrolytic products (Figure 6c).

For both 2,3,6-O-CA and 2,3-O-CA, the largest peak that appeared at retention time of 11 minutes was considered to be main hydrolytic products which were exceeding the limit of the exclusion volume. The retention time of this peak was earlier than that of maltoheptaose with retention time of 9 minutes, suggesting that this large peak could be attributed to mass of oligomers with DP over 8. According to the previous studies, cellulose oligomers below octamer are known as water-soluble [22] and the solubility of cellulose in water can be improved by partial acetylation and resulting deformation of hydrogen bonding [21]. These reports are also supporting that the hydrolytic products of CAs are mainly consisting of oligomers above octamer. In addition, for both 2,3,6-O-CA and 2,3-O-CA, the second largest peak appeared at the elution time of 16 minutes, and whose molecular weight was corresponding to glucose. Therefore, it was suggested that the second major hydrolytic products were a monomer.

Celluclase is a the generic name of the enzymes that hydrolyze cellulose, consisting of endo-glucanase (EG) which randomly cleaves glycosyl bond at the middle of cellulose chain, and cellobiohydrase $(\mathrm{CBH})$ which cleaves glycosyl bond at both ends of cellulose chain, and $\beta$-glucosidase which subsequently hydrolyze cellulose or cellobiose chains to glucose monomers [23]. Both 2,3,6-O-CA and 2,3-O-CA seemed to be hydrolyzed in similar way to 
cellulose by cellulase. It was considered that the oligomers above octamer were produced by random hydrolysis of the middle of CA chain by end-glucanase (EG). We suggest that glucose monomers were produced from further hydrolysis of cellobiose or glucose unit from the ends of $\mathrm{CA}$ chains by $\mathrm{CBH}$ and $\beta$-glucosydase and that further hydrolysis were inhibited by the presence of the acetyl groups at the AGU at the end of CA chain.

Interestingly, in the case of 2,3-O-CA with DS of 0.4 and 1.3, the peaks attributed to oligomers from dimer to heptamer were apparently observed as shown in Figure $6 \mathrm{~b}$, while they were not observed for 2,3,6-O-CA. This result strongly suggested that 2,3-O-CA was hydrolyzed more easily than 2,3,6-O-CA at the middle of CA chain by EG even when $\mathrm{C} 2$ and C3 positions are substituted. In other words, the hydrolysis of CA by EG was inhibited by the presence of 6-O-acetyl group. It could be concluded that 2,3-O-CA, whose C6-hydroxy group is remaining unsubstituted, allows EG to bind onto cellulose main-chain and makes itself more susceptible to enzymatic degradation, and that the free hydroxyl group at C6 position was regarded as crucial binding site for EG for hydrolysis of cellulose chain.

The de-acetylated cellulose was producing more hydrolytic products at 12 hour incubation at this enzyme concentration, suggesting that the enzymes were remaining active at this point. The hydrolytic oligomers from 2,3-O-CA were considered to be final products that could not be any further by cellulase due to the structural reason. We suspect that further hydrolysis of oligomers from 2,3-O-CAs by $\mathrm{CBH}$ or $\beta$-glucosydase were inhibited due to the presence of acetyl groups at $\mathrm{C} 2$ and $\mathrm{C} 3$ positions. It has been reported that binding of the $\mathrm{CBH}$ is considered to occur at C6 hydroxyl group [24]. Our present study suggested that acetylation of $\mathrm{C} 2$ and $\mathrm{C} 3$ positions prevented hydrolysis of $\mathrm{CA}$ main-chain by $\mathrm{CBH}$ or $\beta$-glucosydase even at low DS and that free hydroxyl groups at C6 position is not sufficient for $\mathrm{CBH}$ activation.

Generally, the selectivity of enzymatic reaction should be very high. However, it was difficult to judge whether the partially acetylated AGU were recognized by cellulase, or just non-substituted AGU were hydrolyzed. It has been very difficult to determine the distribution of acetyl groups on cellulose chain, inter and intra molecularly. In addition, as far as we know, there has been no study on degradation of CA by specific enzyme such as EG, $\mathrm{CBH}$, and $\beta$-glucosydase, with a relation to its molecular structure. In future, more detailed specific enzyme activity on hydrolysis site in CA chain will be studied by further structural analyses of hydrolytic products for example by their fractionation by HPLC and GC or NMR analyses of each fraction.

\section{Conclusion}

We have prepared randomly and regioselectively substituted 2,3,6-O-CA (DS $=0.4$, 1.2, and 2.1, $\left.\mathrm{DP}_{\mathrm{n}}=248\right)$ and 2,3-O-CA (DS = 0.4, 1.3, and 2.0, $\left.\mathrm{DP}_{\mathrm{n}}=54\right)$. Both 2,3,6-O-CA and 2,3-O-CA were submitted to enzymatic degradation test using cellulase and the 
concentration of hydrolyzed product was analyzed by the reducing sugar analyses using glucose standards. CAs with lower DS (0.4) were more hydrolyzed compared to CAs with higher DS (1.2 or 1.3) and that CAs with DS over 2 were not hydrolyzed regardless of substitution site. The degradability of 2,3-O-CAs (DS $=0.4$ and 1.3 ) turned out to be higher than that of 2,3,6-O-CAs (DS $=0.4$ and 1.2) even without considering the effect of molecular weight on the reducing sugar concentration of the hydrolyzed products. HPLC analyses revealed that both 2,3,6-O-CA and 2,3-O-CA produced oligomers over octamer and dimer and monomer as main products. In addition, 2,3-O-CAs ( $\mathrm{DS}=0.4$ and 1.3) produced oligomers including trimer to heptamer while 2,3,6-O-CAs did not, and these oligomers were not hydrolyzed further. This suggested that 2,3-O-CA could be hydrolyzed more easily by EG via cleavage at the middle of the cellulose chain and that free hydroxyl group at $\mathrm{C} 6$ position is crucial for enzymatic degradation by $\mathrm{EG}$, and which also contributed to its higher degradability. Acetylation of $\mathrm{C} 2$ and $\mathrm{C} 3$ positions seemed to prevent hydrolysis of $\mathrm{CA}$ main-chain by $\mathrm{CBH}$ or $\beta$-glucosydase even at low DS suggesting free hydroxyl groups at $\mathrm{C} 6$ position is not sufficient for $\mathrm{CBH}$ activation. These results revealed that degradation behavior of CA could be controlled by regioselective substitution.

\section{Acknowledgements}

This study was supported by JST-ALCA and a Grant-in-Aid for Scientific Research (A) (No.22245026 and 26248044) (to T.I.) from the Japan Society for the Promotion of Science (JSPS).

\section{References}

[1] Edgar KJ, Buchanan CM, Debenham JS, Rundquist PA, Seiler BD, Shelton MC, et al. Advances in cellulose ester performance and application. Progress in Polymer Science. 2001;26:1605-88.

[2] C. E. Reid, Breton EJ. Water and ion flow across cellulosic membranes. Journal of Applied Polymer Science. 1959;1:133-43.

[3] Mohanty AK, Misra M, Hinrichsen G. Biofibres, biodegradable polymers and biocomposites: An overview. Macromolecular Materials and Engineering. 2000;276-277:1-24.

[4] Gu J-D, Eberiel DT, McCarthy SP, Gross RA. Cellulose acetate biodegradability upon exposure to simulated aerobic composting and anaerobic bioreactor environments. Journal of environmental polymer degradation. 1993;1:143-53.

[5] Buchanan CM, Gardner RM, Komarek RJ. Aerobic biodegradation of cellulose acetate. Journal of Applied Polymer Science. 1993;47:1709-19.

[6] Komarek RJ, Gardner RM, Buchanan CM, Gedon S. Biodegradation of radiolabeled cellulose acetate and cellulose propionate. Journal of Applied Polymer Science. 1993;50:1739-46.

[7] Gardner RM, Buchanan CM, Komarek R, Dorschel D, Boggs C, White AW. Compostability of 
cellulose acetate films. Journal of Applied Polymer Science. 1994;52:1477-88.

[8] Rivard CJ, Adney WS, Himmel ME, Mitchell DJ, Vinzant TB, Grohmann K, et al. Effects of natural polymer acetylation on the anaerobic bioconversion to methane and carbon dioxide. Applied Biochemistry and Biotechnology. 1992;34:725-36.

[9] Jiang L, Hinrichsen G. Biological degradation of cellulose acetate films: Effect of plasticizer. Die Angewandte Makromolekulare Chemie. 1997;253:193-200.

[10] Cantor PA, Mechalas BJ. Biological degradation of cellulose acetate reverse-osmosis membranes. Journal of Polymer Science Part C: Polymer Symposia. 1969;28:225-41.

[11] Reese ET. Biological degradation of cellulose derivatives. Industrial and engineering chemistry. 1957;49:89-93. [12] Sakai K, Yamauchi T, Nakasu F, Ohe T. Biodegradation of cellulose acetate by Neisseria sicca. Bioscience Biotechnology and Biochemistry. 1996;60:1617-22.

[13] Moriyoshi K, Ohmoto T, Ohe T, Sakai K. Purification and characterization of an esterase involved in cellulose acetate degradation by Neisseria sicca SB. Bioscience Biotechnology and Biochemistry. 1999;63:1708-13.

[14] Glasser WG, McCartney BK, Samaranayake G. Cellulose derivatives with low degree of substitution.3. The biodegradability of cellulose esters using a simple enzyme assay. Biotechnology progress. 1994;10:214-9. [15] Puls J, Wilson SA, Hölter D. Degradation of Cellulose Acetate-Based Materials: A Review. Journal of Polymers and the Environment. 2010;19:152-65.

[16] Roesser DS, McCarthy SP, Gross RA, Kaplan DL. Effects of Substitution Site on Acetyl Amylose Biodegradability by Amylase Enzymes. Macromolecules. 1996;29:1-9.

[17] McCormick CL, Callais PA. Derivatization of Cellulose In Lithium-Chloride And N-N-Dimethylacetamide Solutions. Polymer. 1987;28:2317-23.

[18] Gömez JAC, Erler UW, Klemm DO. 4-methoxy substituted trityl groups in 6-O protection of cellulose: Homogeneous synthesis, characterization, detritylation. Macromolecular Chemistry and Physics. 1996;197:953-64.

[19] Iwata T, Azuma JI, Okamura K, Muramoto M, Chun B. Preparation and NMR assignments of cellulose mixed esters regioselectively substituted by acetyl and propanoyl groups. Carbohydrate research. 1992;224:277-83.

[20] Tezuka Y, Tsuchiya Y. Determination of Substituent Distribution in Cellulose Acetate by Means of a 13-C NMR Study on Its Propionated Derivative. Carbohydrate Research. 1995;273:83-91.

[21] Samejima M, Sugiyama J, Igarashi K, Eriksson K-EL. Enzymatic hydrolysis of bacterial cellulose. Carbohydrate Research. 1997;305:281-8.

[22] Isogai A, Usuda M. Preparation of low-molecular-weight celluloses using phosphoric-acid. Mokuzai gakkaishi. 1991;37:339-44. [23] Payne CM, Knott BC, Mayes HB, Hansson H, Himmel ME, Sandgren M, et al. Fungal Cellulases. Chemical Reviews. 2015;115:1308-448.

[24] Koivula A, Reinikainen T, Ruohonen L, Valkeajarvi A, Claeyssens M, Teleman O, et al. The active site of Trichoderma reesei cellobiohydrolase II: The role of tyrosine 169. Protein Engineering. 
1996;9:691-9. 


\section{Figure legends}

Figure 1. Syntheses of (a) 2,3,6-O-CA and (b) 2,3-O-CA.

Figure 2. ${ }^{1} \mathrm{H}-\mathrm{NMR}$ spectra of (a) perpropionylated 2,3,6-O-CA $(\mathrm{DS}=1.2)$ and (b) 2,3-O-acetyl-6-O-trytyl-cellulose (DS $=1.3$ ) and ${ }^{13} \mathrm{C}-\mathrm{NMR}$ spectra of (c) perpropionylated 2,3,6-O-CA (DS = 1.2) and perpropionylated 2,3-O-CA (DS = 1.3) in $\mathrm{CDCl}_{3}$.

Figure 3. Reducing sugar concentration as function of incubation time at enzyme concentration of $0.7 \mathrm{u} / \mathrm{mL}$ for (a) 2,3,6-O-CAs (DS = 0.4 ( $\bullet), \mathrm{DS}=1.2(\boldsymbol{\Delta}), \mathrm{DS}=2.1(\mathbf{\square}))$ and (b) 2,3-O-CAs (DS = 0.4 ( $\diamond), \mathrm{DS}=1.3(\Delta), \mathrm{DS}=2.0(\square)$.

Figure 4. Reducing sugar concentration as function of incubation time at enzyme concentration of $7 \mathrm{u} / \mathrm{mL}$ for (a) cellulose with $\mathrm{DP}_{\mathrm{n}}$ of $248(\bullet)$ and 2,3,6-O-CAs (DS $=0.4(\bullet)$ ), $\mathrm{DS}=1.2(\boldsymbol{\Delta}), \mathrm{DS}=2.1(\mathbf{\square}))$ and (b) cellulose with DP $\mathrm{n}_{\mathrm{n}} 54(\mathrm{\circ})$ and 2,3-O-CAs (DS = 0.4 $(\diamond), \mathrm{DS}=1.3(\Delta), \mathrm{DS}=2.0(\square))$

Figure 5. Relative reducing sugar concentration of hydrolytic products of (a) 2,3,6-O-CAs $(\mathrm{DS}=0.4(\diamond), 1.2(\mathbf{\Delta}), 2.1(\mathbf{\square}))$ and $(\mathrm{b})$ 2,3-O-CAs $(\mathrm{DS}=0.4(\diamond), 1.3(\Delta), 2.0(\square))$ to cellulose with the corresponding $\mathrm{DP}_{\mathrm{n}}$.

Figure 6. HPLC profiles for hydrolytic products from (a) 2,3,6-O-CAs and (b) 2,3-O-CAs after 12 hour incubation and (c) standards.

Table 1 Characteristics of 2,3,6-O-CAs and 2,3-O-CAs. 
Table 1 Characteristics of 2,3,6-O-CAs and 2,3-O-CAs.

\begin{tabular}{|c|c|c|c|c|c|c|c|c|c|c|}
\hline \multirow{2}{*}{ Compounds } & \multirow{2}{*}{$\begin{array}{l}\text { Acetylation } \\
\text { condition }\end{array}$} & \multirow{2}{*}{$\begin{array}{l}\text { Total } \\
\text { acetyl } \\
\text { DS }\end{array}$} & \multicolumn{3}{|c|}{$\begin{array}{c}\text { Distribution of acetyl } \\
\text { groups } \\
\end{array}$} & \multirow{2}{*}{$M_{\mathrm{w}} \times 10^{-4}$} & \multirow{2}{*}{$M_{\mathrm{n}} \times 10^{-4}$} & \multirow{2}{*}{$M_{\mathrm{w}} / M_{\mathrm{n}}$} & \multirow{2}{*}{$\mathrm{DP}_{\mathrm{n}}$} & \multirow{2}{*}{$\begin{array}{c}\text { Initial } \\
\text { degradation } \\
\text { rate }(v)(\mathrm{mM} / \mathrm{h})\end{array}$} \\
\hline & & & DS (C2) & DS (C3) & DS (C6) & & & & & \\
\hline $2,3,6-O-\mathrm{CA}$ & $40^{\circ} \mathrm{C}, 0.5 \mathrm{~h}$ & 0.4 & 0.0 & 0.0 & 0.4 & 11 & 7.2 & 1.6 & 248 & 0.0 \\
\hline $2,3,6-O-\mathrm{CA}$ & $40^{\circ} \mathrm{C}, 2.0 \mathrm{~h}$ & 1.2 & 0.4 & 0.2 & 0.6 & 11 & 7.2 & 1.6 & 248 & 0.0 \\
\hline $2,3,6-O-C A$ & $40^{\circ} \mathrm{C}, 3.0 \mathrm{~h}$ & 2.1 & 0.9 & 0.2 & 1.0 & 11 & 7.2 & 1.6 & 248 & 0.0 \\
\hline $2,3-O-\mathrm{CA}$ & $40^{\circ} \mathrm{C}, 0.2 \mathrm{~h}$ & 0.4 & \multicolumn{2}{|c|}{0.4} & 0.0 & 3.2 & 1.6 & 2.0 & 54 & 11.4 \\
\hline $2,3-O-C A$ & $60^{\circ} \mathrm{C}, 0.2 \mathrm{~h}$ & 1.3 & 1.0 & 0.3 & 0.0 & 3.2 & 1.6 & 2.0 & 54 & 10.2 \\
\hline 2,3-O-CA & $60 \stackrel{\circ}{\mathrm{C}}, 18 \mathrm{~h}$ & 2.0 & 1.0 & 1.0 & 0.0 & 3.2 & 1.6 & 2.0 & 54 & 0.0 \\
\hline
\end{tabular}


(a)
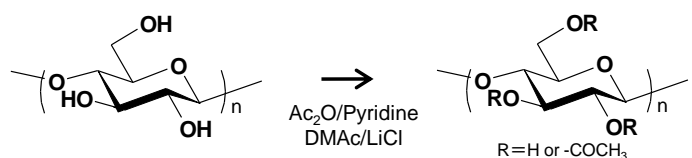

cellulose

\section{$2,3,6-O-C A$}

(b)

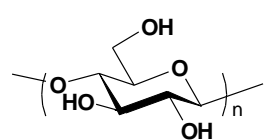

cellulose

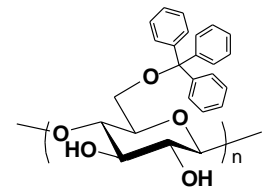

6-O-tritylcellulose

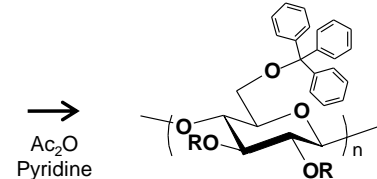

$\mathrm{R}=\mathrm{H}$ or $-\mathrm{COCH}_{3}$

2,3-O-acetyl-6-Otrityl-cellulose

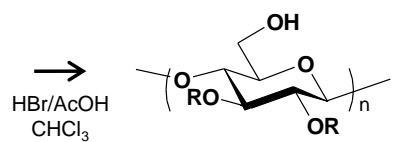

$\mathrm{R}=\mathrm{H}$ or $-\mathrm{COCH}_{3}$

Figure 1. Synthesis of (a) 2,3,6-O-CA and (b) 2,3-O-CA. 

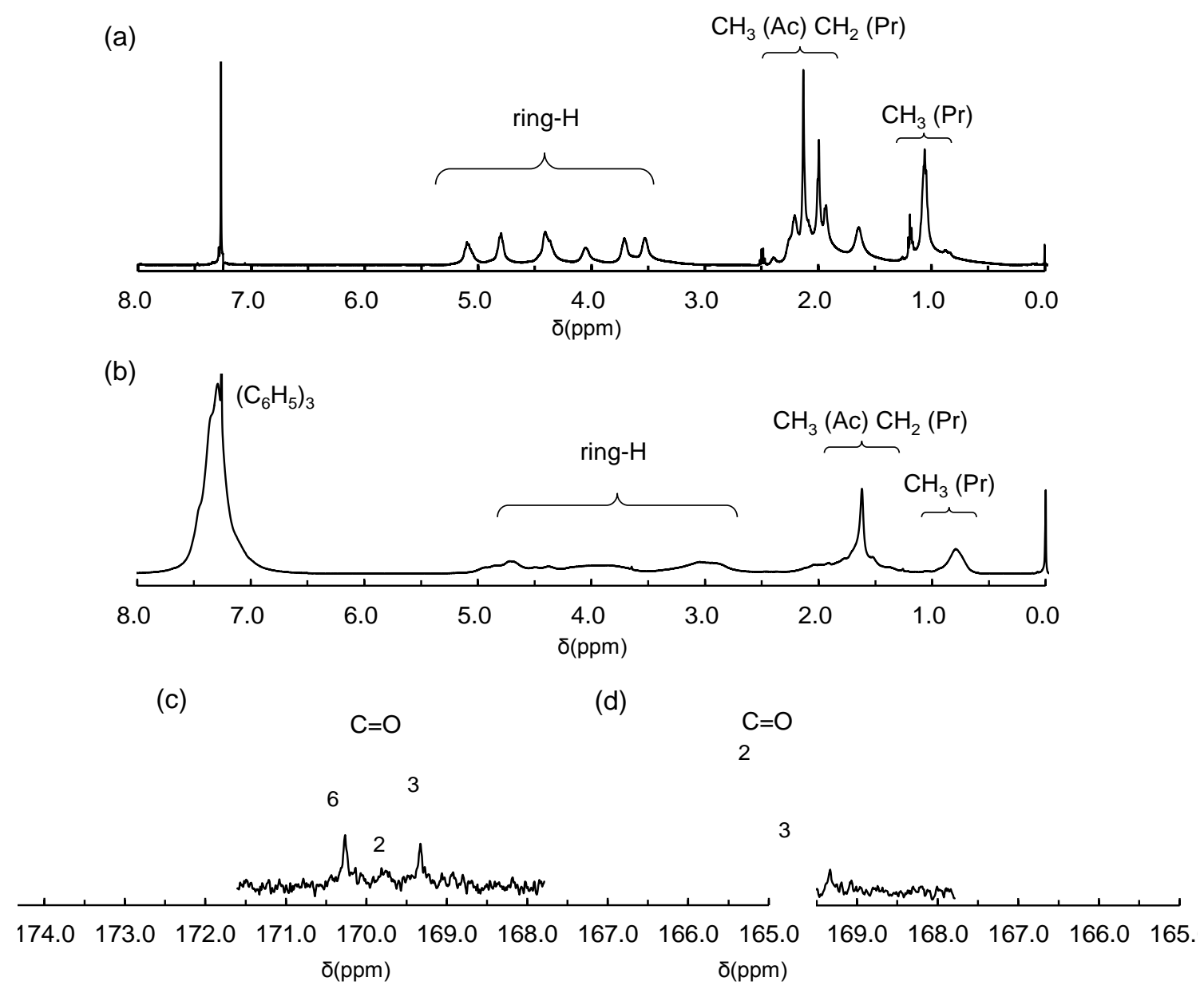

Figure 2. ${ }^{1} \mathrm{H}$-NMR spectra of (a) perpropionylated $2,3,6-\mathrm{O}-\mathrm{CA}(\mathrm{DS}=1.2)$ and $(\mathrm{b}) 2,3-\mathrm{O}$ acetyl-6-O-trytyl-cellulose ( $\mathrm{DS}=1.3$ ) and ${ }^{13} \mathrm{C}$-NMR spectra of (c) perpropionylated $2,3,6$ $O-C A(D S=1.2)$ and (d) perpropionylated $2,3-O-C A(D S=1.3)$ in $\mathrm{CDCl}_{3}$. 


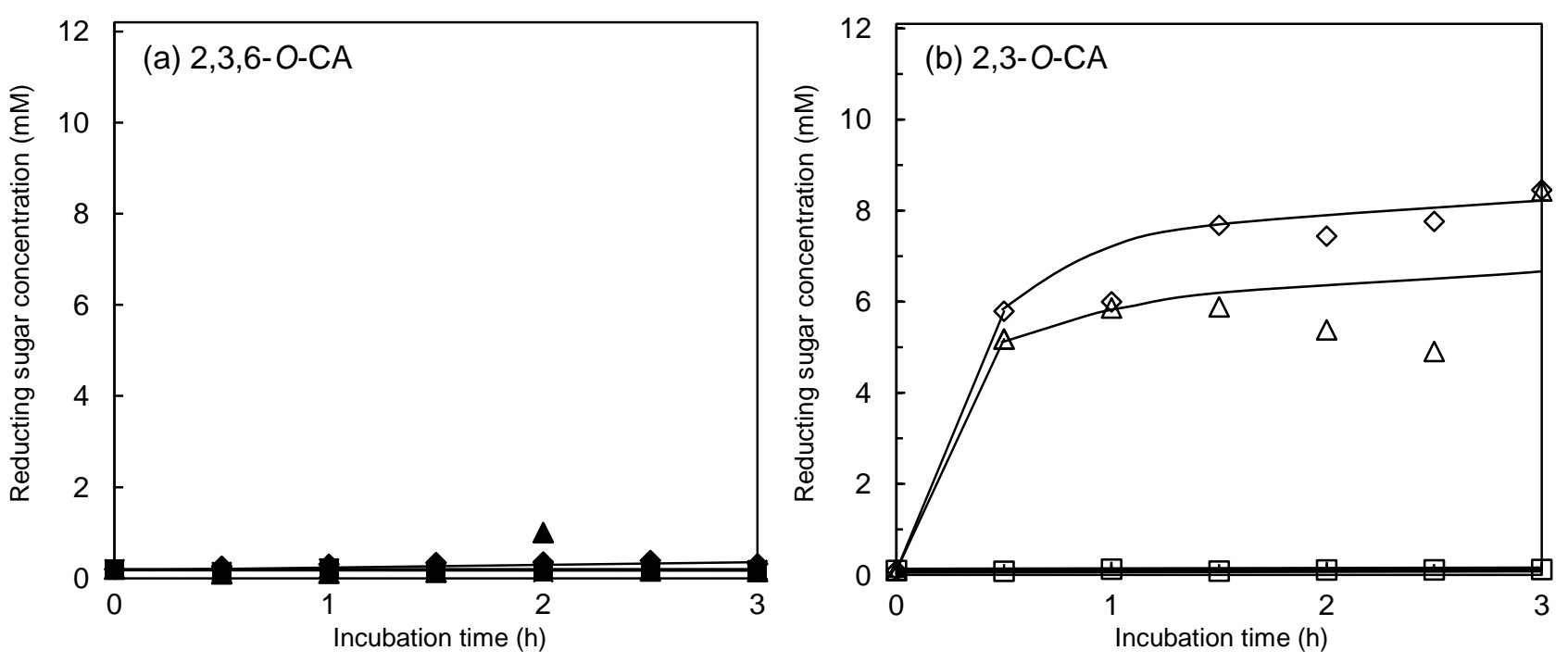

Figure 3. Reducing sugar concentration as function of incubation time at enzyme concentration of $0.7 \mathrm{u} / \mathrm{mL}$

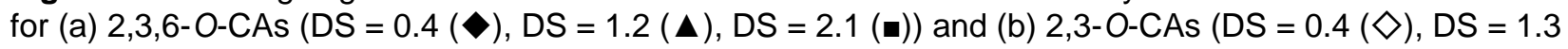
$(\triangle)$, DS $=2.0(\square)$. 

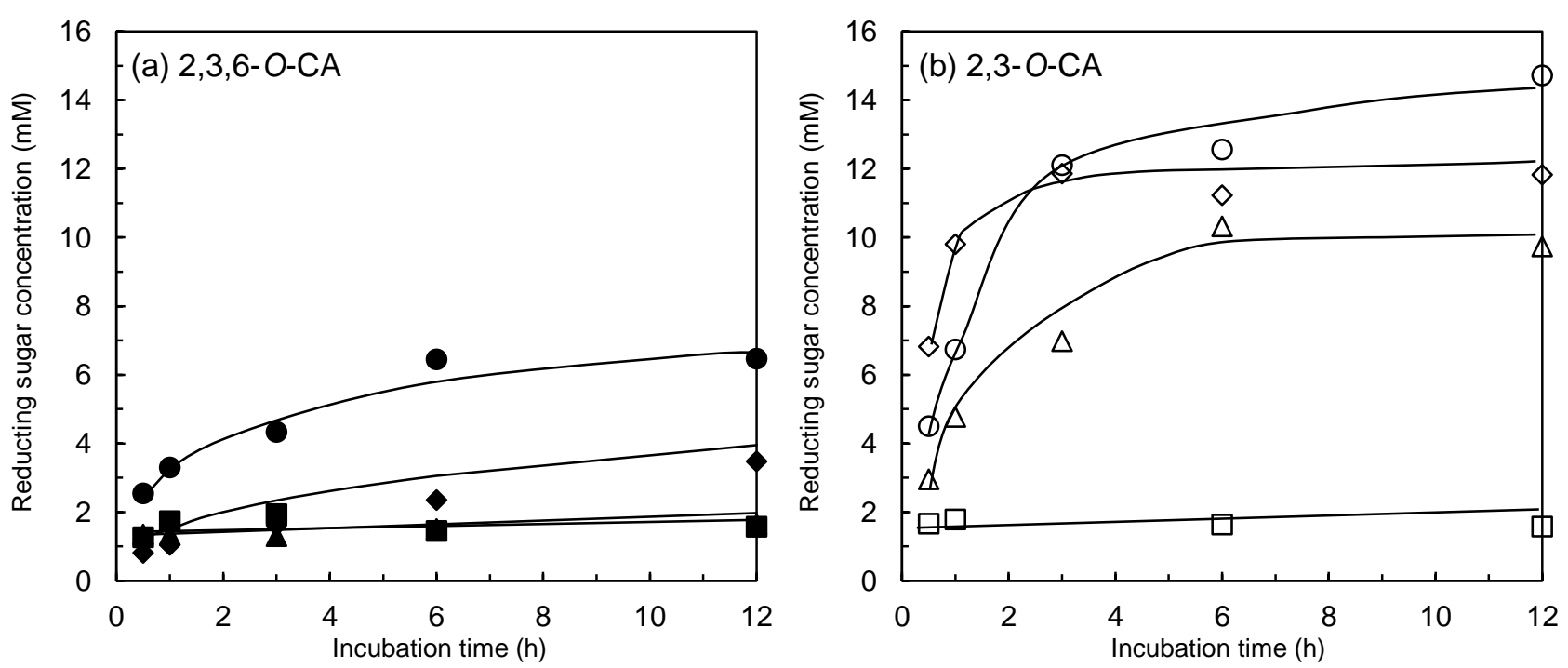

Figure 4. Reducing sugar concentration as function of incubation time at enzyme concentration of 7 $\mathrm{u} / \mathrm{mL}$ for (a) cellulose with $\mathrm{DP}_{\mathrm{n}}$ of $248(\bullet)$ and 2,3,6-O-CAs $(\mathrm{DS}=0.4(\bullet), \mathrm{DS}=1.2(\mathbf{\Delta}), \mathrm{DS}=2.1(\mathbf{\bullet}))$

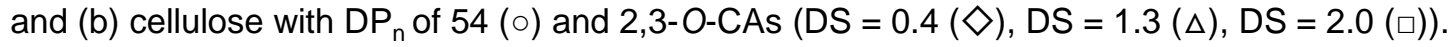



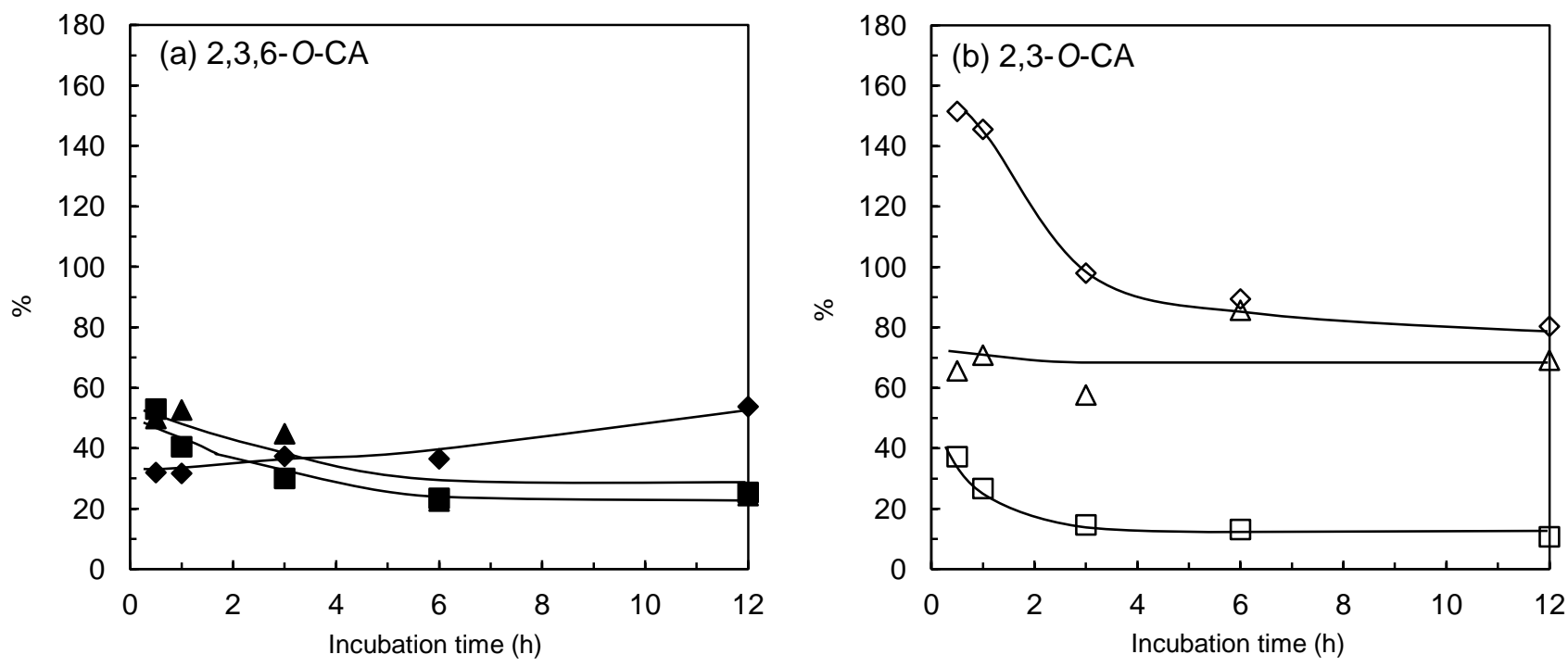

Figure 5. Relative reducing sugar concentration of hydrolytic products of (a) 2,3,6-O-CAs (DS=0.4 ( $), 1.2$ $(\mathbf{\Delta}), 2.1(\mathbf{a}))$ and $(\mathrm{b})$ 2,3-O-CAs (DS=0.4 $(\diamond), 1.3(\Delta), 2.0(\square))$ to cellulose with the corresponding $\mathrm{DP}_{\mathrm{n}}$. 

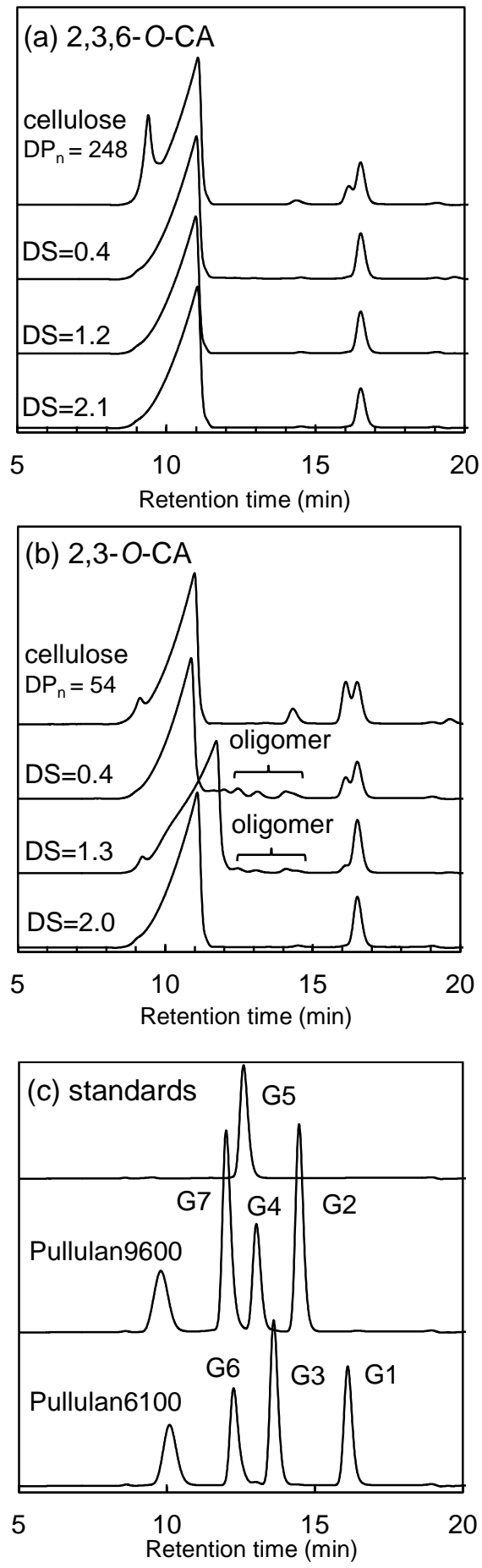

Figure 6. HPLC profiles for hydrolytic products from (a) 2,3,6-O-CAs and (b) 2,3-O-CAs after 12 hour incubation and (c) standards. 